\title{
Monterrey y su ámbito regional (1850-1910). Referencia histórica y sugerencias metodológicas*
}

\section{Mario Cerutti}

Lo que se expondrá en este artículo no es más que un racimo limitado de reflexiones alimentadas por tres vertientes principales: l) nuestra propia experiencia de investigación, concentrada en un determinado espacio regional del México decimonónico; 2) lo aportado por un grueso número de colegas que - desde mediados de los años 70 - han indagado el siglo xIx por medio de una minuciosa auscultación de fuentes primarias asentadas en archivos de provincia; 3) la revisión parcial de la producción historiográfica que sobre objetos de estudio análogos se ha realizado en los últimos tiempos en países como Argentina, Colombia y - muy particularmente- España.

Lo que aquí se comentará y sugerirá está centralmente dedicado al siglo xix en México. Empero, algunos de estos planteamientos podrían resultar válidos, quizás, para un considerable grupo de sociedades latinoamericanas y para ciertos casos europeos.

Las proposiciones metodológicas a desarrollar se concentrarán entonces en el ámbito de los estudios históricos y con referencia especial a un periodo que - por sus características más íntimas y definitorias - parece demandar un afinamiento o una más pertinente conceptualización de lo regional.

Aunque suponemos que algunas facetas de estas propuestas serían factibles de aplicar a otros lapsos históricos - por ejemplo, a situaciones más recientes - dejamos que las conclusiones al respecto las extraigan quienes tengan ocasión de analizar el presente texto.

En la medida en que el siglo xIx se ha convertido en México en objeto sistemático de investigaciones sustentadas en fuentes primarias -consecuencia de la importancia decisiva que se le asigna para la explicación de procesos más cercanos y del crecimiento académico suscitado en provincia - se ha tornado preponderante una forma de enfocar esta etapa, una manera de sondearla: es lo que podríamos llamar, justamente, una visión regional de ese lapso histórico.

La vinculación ascendente que en los últimos años se ha observado entre una más atenta auscultación del siglo xix y una perspectiva que tiende a acentuar el estudio centrado en espacios territoriales menores al que finalmente daría sustento al Estado-nación es, a la vez, fruto de un ejercicio metodológico que visualiza la enorme difi-

* Versión revisada de la ponencia presentada en el coloquio "Mexican Regions: Comparative History and Development", Universidad de California/San Diego, diciembre de 1988. 
cultad de reconocer una historia homogénea a escala global. Ya que una historia nacional, en sentido estricto, es decir, como un proceso capaz de saturar en términos territoriales, sociales y políticos lo que hoy llamamos México, habría sido el resultado de la formación del Estado-nación, y no su precedente. Hasta que este Estado-nación quedó provisionalmente definido - fenómeno que coincidiría con la gestión de Porfirio Díaz, desde los 80- parece más factible encontrar y explicar un conjunto heterogéneo de historias (de procesos) recorridas en espacios regionales que finalmente quedarían encerrados en el actual marco mexicano.

De la articulación voluntaria o forzada de aquellos espacios regionales surgiría así, un Estado nacional moderno. Y, con ello, un aparato político-administrativo centralizado, una economía marcadamente nacional, clases sociales con características nacionales e inevitablemente un dominio de clase capaz de extenderse multirregionalmente. ${ }^{1}$

Mientras se arribaba a tal consecuencia histórica, esta centuria presentó en México una complejidad tal que sólo con una fuerte dosis de anacronismo puede arribarse a la conclusión de que lo que sucedía a lo largo y ancho de su vasta geografía - partida por la mitad, hay que recordar, tras la guerra con Estados Unidos - era efecto de decisiones y medidas adoptadas por un supuesto poder central. Para la adecuada interpretación de un siglo que podría definirse como una transición entre el desmoronamiento del viejo sistema colonial y la rearticulación espacial que con cimientos capitalistas termina de afianzarse hacia los albores de la centuria siguiente, es obligado entonces tener en cuenta los espacios, además de la cronología. De allí que su estudio y las investigaciones que lo alimentan actualmente involucren como fórmula difícil de descartar la perspectiva regional.

Claro está que este panorama no sería exclusivo de México, ni de América Latina siquiera. Si revisar casos como el colombiano o el argentino podría conducirnos a una apreciación análoga, una mirada atenta sobre lo sucedido en Italia, Alemania o España - sin dejar de lado ese caso espectacular de formación de un Estado-nación que fue Estados Unidos- quizás llevase a conclusiones similares. ${ }^{2}$

1 La edificación del Estado-nación en América Latina fue posible a partir de las relaciones que tejieron, precisamente, poderes con sustento regional. Este proceso obligó a que se alcanzaran ciertos acuerdos entre esas formas insulares de dominación o llevó a que algunas fracciones dominantes regionales mostraran suficiente fortaleza como para pasar a constituirse en el nudo de un poder central que sometía al resto de las porciones territoriales que se integrarían - geográfica y políticamente- al Estado nacional. Es lo que sucedió en aquellos países que devendrían estados nacionales multirregionales (particularmente: Brasil, México, Argentina). Cuando no hubo posibilidad de acuerdo - logrado ya por la vía del consenso, ya por la de la coerción y de la fuerza militar -, el poder regional se transformó directamente en base política de un nuevo Estado-nación: los pequeños países centroamericanos, o el caso de Uruguay, en el sur, ejemplifican este tipo de resultados.

2 Desde esta perspectiva regional, los procesos protagonizados durante el siglo XIX por algunas sociedades latinoamericanas no parecen excesivamente distintos a los de ciertas sociedades europeas. Casos como los de México y España podrían ser objeto de no pocos estudios paralelos. Ambos países estuvieron en la periferia más cercana de la revolución industrial, y transitaron durante el XIX un conjunto de situaciones cotejables. Quizás sea más fructífero profundizar en un estudio comparativo entre el siglo XIX mexicano con el español que con el de Haití o Paraguay. Intentos en este sentido se encuentran en Mario Cerutti y Menno Vellinga, Burguesias e industria en América Latina y Europa del sur, Alianza Editorial, Madrid, 1989, y Mario Cerutti, "Empresariado regional, sociedad anónima e industria pesada en sociedades no industrializadas. 
Ha favorecido el desenvolvimiento de esta visión regional el hecho de que, en México, haya comenzadó a estimularse con fuerza, desde hace poco más de una década, la investigación en provincia. Si bien continúa siendo abrumadora la diferencia de medios cuando se piensa en lo que concentra su ciudad capital, también es visible que no sin dificultades y precariedades en distintas universidades y urbes del interior ha germinado y crece la indagación que apunta a lo local, lo comarcal o lo regional.

Es llamativo además que desde centros especializados del mismo Distrito Federal la incursión en el siglo xix parece haber obligado a limitar los objetos de estudio a dimensiones geográficas más modestas. Se han diseñado trabajos en los que resulta notoria la modificación de perspectiva: ya no se procura esclarecer la historia de todo México, sino verificar lo acaecido en contextos regionales que, en todo caso, sitúan la ciudad capital y a sus agentes sociales en un perímetro más pertinente. ${ }^{3}$ En última instancia sería una forma de aceptar la diversidad de situaciones, por momentos extrema, que se produjeron durante este periodo (que, bueno es señalarlo, se prolonga firmemente hasta las décadas iniciales del siglo $\mathrm{xx}$ ). Deviene de ello, obviamente, una mayor cautela en las afirmaciones cuando de una visión global se trata. Y, simultáneamente, una más acentuada solidez en las conclusiones cuando se hace alusión al espacio indagado.

Nos permitiremos ahora practicar una referencia histórica concreta sobre Monterrey y su ámbito regional, en el norte fronterizo, entre 1850 y 1910. La descripción de algunos de los procesos vertebrales que se dieron en esta porción del territorio mexicano contribuirá a esclarecer nuestros planteamientos en torno a la cuestión regional.

\section{II}

E1 momento más antiguo que recordará esta referencia sobre Monterrey fue abierto por uno de los hechos más críticos del siglo: la guerra con Estados Unidos (1846-47), que acercó abruptamente la frontera septentrional a aquella ciudad y alteró drásticamente sus funciones respecto a una amplia área del norte oriental del país.

Desde entonces y hasta el estallido de la revolución muchas cosas cambiaron en esta urbe y en su entorno. Entre las más significativas estuvo su ascendente posición en tan extenso marco territorial. Y, muy conectada con esta tendencia se perfiló la emergencia de una burguesía con bases regionales que surgió, creció y se entrelazó sobre

Monterrey y Bilbao a principios de siglo" en III Encuentro sobre empresarios, Tlaxcala, octubre, mimeografiado.

3 Investigadores que señalan esta tendencia son, entre otros, Juan Felipe Leal, Mario Huacuja Rountree, Héctor Díaz-Polanco, Eduardo Flores Clair, Mario Ramírez Rancaño, María Teresa Huerta y Guillermo Beato. Carlos Marichal, por su lado, insistió en su trabajo reciente "Los empresarios y las finanzas de la ciudad de México. Tres estudios de caso (1780-1900)", en el III Encuentro sobre empresarios, en hablar de los "comerciantes de la ciudad de México", al referirse a los grupos burgueses que operaban desde la capital a fines del xvin y durante el xix. Negó así consenso a quienes suponen que la burguesía que se formaba durante el XIX residía exclusivamente en la ciudad capital; supuesto que, observado desde los estudios regionales es completamente descartable. (Mario Cerutti, "Contribuciones recientes y relevancia de la investigación regional sobre la segunda parte del siglo xIx en México", Boletín Americanista, Universidad de Barcelona, núm. 37, 1987.) 
tres elementos visiblemente decisivos: a) una acumulación previa de capitales efectuada con mecanismos que contaron con el comercio como una de sus herramientas primordiales, que excluyó casi totalmente las formas capitalistas de producción, y que ocurrió en las décadas críticas que siguieron al cambio fronterizo; $b$ ) un traslado masivo de esos capitales y de otros bienes a la producción capitalista a partir de 1890, en un movimiento que usufructuó las condiciones generadas por el porfiriato, los renovados vínculos que se entretejían con la economía norteamericana y la estructuración y expansión del mercado interior; c) la puesta en marcha de un destacado brote de industrialización, con una característica no repetida en la América Latina de esos años: la producción en gran escala de bienes dedicados al propio proceso productivo, como base de la industria pesada.

Desde 1850 y hasta aproximadamente 1890 , los segmentos burgueses asentados en Monterrey utilizaron no pocos de los instrumentos de acumulación previamente permitidos (y estimulados) por una estructura económica y sociopolítica que si apuntaba, con claras indecisiones, hacia los límites de un Estado-nación, se definía aún en marcos de dimensión regional.

Dentro de estos 40 años destacó, en la fase más lejana del proceso investigado, una coyuntura particularmente rica para ser recordada en nuestra exposición. Fue cuando se intentó con coherencia el reordenamiento que demandaba el noreste de México ante su nueva situación fronteriza: actor fundamental de esa readecuación sería Santiago Vidaurri, gobernador de Nuevo León (y del vecino estado de Coahuila, al que se anexó en 1856) entre 1855 y 1864.

Desde que se levantó en armas contra Antonio López de Santa Anna en mayo de 1855 y se apoderó de Monterrey para luego pasar a controlar Coahuila y a influir sensiblemente en Tamaulipas, el jefe nuevoleonés blandió con firmeza la causa liberal. Pero el matiz -inevitable en esos tiempos - era el siguiente: el liberalismo del noreste colocaba, junto a las propuestas globales de esta corriente, una densa problemática regional, que se nutría de los dilemas que día a día experimentaban los pobladores de esta parte de la frontera y levantaba, por ello, una bandera de claros sesgos autonómicos.

Liberalismo, matriz regional, particularidades locales y exigencias de la vida cotidiana emergían totalmente entremezclados en este núcleo liberal que tuvo a Vidaurri como figura principal, entre su ascenso al gobierno estatal y el momento en que fue destituido por Benito Juárez. ${ }^{4}$

Hasta cuando se agudizaron las disidencias con Juárez, la adhesión al liberalismo resultó consistente y con planteamientos frecuentemente radicales en temas tan delicados como la necesidad de depurar el ejército regular, quitar a la Iglesia católica sus bases de

4 Benito Juárez y Santiago Vidaurri mantuvieron relaciones sumamente tensas en no pocos momentos, pese a que ambos trabajaban por la causa liberal. Desde mediados de 1863, Juárez comenzó a insistir en una antigua solicitud; que se devolvieran al erario federal los ingresos aduanales, en particular los de Piedras Negras (que vivían entonces un momento de prosperidad por la guerra de secesión norteamericana). Vidaurri se negó terminantemente, en tanto las tropas que respondían a Juárez subían hacia el norte por la presión francesa. En un clima de extrema agresividad, Juárez obligó al gobernador de Nuevo León-Coahuila a salir del país y reintegró a Coahuila su autonomia. Vidaurri se adheriria posteriormente al imperio de Maximiliano. 
poder o impulsar la soberanía popular. ${ }^{5}$ Un punto en el que la concepción liberal surgió y se mantuvo con fuerza fue el relativo al comercio: con el respaldo vigoroso de los intermediarios locales y del sur de Texas, se sostenía que era menester abrir las fronteras al intercambio internacional por ser una savia vivificante para el progreso y para un más eficaz funcionamiento de las zonas de frontera. Este enfoque estaba condicionado, ya se señaló, por una mirada que respondía a las circunstancias específicas del marco regional. Entre sus dilemas vertebrales sobresalía la lucha contra los contingentes de indios seminómadas (apaches, comanches) que azotaban al inmenso territorio adherido a Texas. ${ }^{6}$ Un segundo dato de la realidad local era la convivencia con Estados Unidos. En más de una ocasión, bandas texanas incursionaron con fines diversos en territorio mexicano. En una oportunidad, en octubre de 1855, incendiaron Piedras Negras. Las correrías texanas mantenían en alto el fantasma de renovadas invasiones norteamericanas. El noreste liberal proclamó aquí, también, un papel activo: el de defensor de la integridad territorial de un Estado-nación que aspiraba a construir y compartir.

Las demandas para que se llevaran a cabo políticas de colonización, la necesidad de aumentar el cuerpo demográfico en estos espacios vacíos, la urgencia por establecer un orden aduanal y arancelario que estimulara el comercio y la angustiosa necesidad de recursos que sostuvieran el readecuamiento que los tiempos exigían en la frontera, se contaban entre las premuras cotidianas, para las que no llegaban soluciones eficaces desde el centro. Ni liberales ni conservadores estaban en condiciones de ofrecerlas, quizá por una razón elemental: hacia mediados de siglo, y en especial en esta coyuntura, era casi inexistente una verdadera administración central. Y el peso de todas estas responsabilidades tenía que ser asumido y resuelto por los poderes con sustento regional.

Cuando estalló la guerra de Reforma - contienda civil que se prolongaría con la ocupación francesa- los problemas se acentuaron. La respuesta del noreste liberal a la guerra civil fue la construcción de un ejército que se nutrió con el contexto más aledaño. Hombre de su época, Vidaurri movilizó y encabezó más de 5000 soldados aptos tanto para las luchas civiles como para la antigua y casi casera contienda contra "los bárbaros". Con esta fuerza armada se mantuvo además en alerta sobre los conatos texanos y hasta luchó contra sus correligionarios liberales, en defensa de su autonomía. ${ }^{7}$

Pero lo que es importante puntualizar ahora es que el espacio sobre el cual operó Vidaurri incluía el estado limítrofe de Coahuila

${ }_{5}^{5}$ Mario Cerutti, "Poder regional, gobierno central y periodismo liberal en México en años de la Reforma. Santiago Vidaurri y los estados fronterizos del noreste (18551864)", en Alberto Gil Novales (comp.), La prensa en la revolución liberal. España, Portugal y América Latina, Universidad Complutense, Madrid, 1983.

6 José Reséndiz, "La política de Vidaurri y la expulsión de las tribus nómadas en el noreste de México", Universidad Autónoma de Nuevo León, tesis de licenciatura en historia, 1981; Isidro Vizcaya Canales, "El fin de los indios lipanes", en Mario Cerutti (coord.), Nuevo León, Monterrey, el noreste, op. cit., 1987; Mario Cerutti, Economía de guerra y poder regional en el siglo XIX, Archivo General del Estado de Nuevo León, Monterrey, la. parte, 1983.

7 La más grave crisis se planteó con el presidente Ignacio Comonfort, en 1856, tras la unificación formal de Nuevo León y Coahuila. Con la ayuda de tropas tamaulipecas, Comonfort intentó hacer retroceder a Vidaurri en este punto. No lo logró, y finalmente aceptó la resolución del Congreso de no innovar en la materia. 
y, aunque con dificultades, la estratégica Tamaulipas. La unión de Nuevo León-Coahuila y el permanente intento sobre el vecino oriental señalaba que el liberalismo vidaurrista ampliaba su perspectiva más allá del perímetro de un estado-provincia: militar y políticamente apuntaba a la reorganización de un marco más extenso que, decididamente, rebasaba Nuevo León.

Este sistema de poder regional -claramente asentado en el poder militar - tuvo como eje a Monterrey. Una ciudad que se convertiría en pivote político y mercantil del conjunto norestense. Por ello, Monterrey resultó la gran usufructuaria del otro cimiento vidaurrista: el empleo del comercio internacional como fuente de recursos, gracias a lo cual era factible mantener en gran medida aquel funcionamiento militar.

En este aspecto, el uso de la línea de frontera - abruptamente acercada por la derrota frente a Estados Unidos- surgió como un dato clave. Para montar, vestir, armar y alimentar un grueso número de batallones se requerían fondos cuantiosos. $\mathrm{Y}$ ya que el supuesto poder central no era capaz de solventar las necesidades locales -entre otras, la propia guerra - los hombres del noreste tomaban ingresos que, técnicamente, correspondían a una administración federal.

El puente entre comercio y captación de recursos se estructuró con la monopolización relativa del sistema aduanal fronterizo, expandido por Vidaurri. Hemos detallado con amplitud, en trabajos anteriores, lo atinente a estos hechos: ${ }^{8}$ sobre todo porque los documentos revisados verificaban las vinculaciones entre el orden vidaurrista y la fase inicial de formación de capitales en Monterrey. Los mercaderes de la ciudad - a la par de otros del noreste (como Evaristo Madero, por entonces residente en Piedras Negras) y aun del sur de Estados Unidos - se involucraron sin prejuicios en el aprovechamiento de las necesidades de guerra que soportaba Nuevo León-Coahuila.

Al revitalizar o directamente habilitar una serie de puestos aduanales sobre el río Bravo, al pugnar por el control de los puertos marítimos instalados en el Golfo (Matamoros y, en menor medida, Tampico, ambos en la díscola Tamaulipas), el poder regional asentado en Monterrey tendió a adueñarse de la mâs rica y regular fuente de ingresos que entonces existía, no sólo en México sino en todo Latinoamérica: la derivada del comercio exterior, casi exclusivamente reducido a importaciones.

Pero Vidaurri fue más allá; nombró funcionarios, estableció aranceles, vigiló e hizo pasar por Monterrey la circulación del metálico (una savia indispensable para los contactos con el mercado internacional). Desde 1856 desconoció la Ordenanza General de Aduanas promulgada por el presidente liberal Ignacio Comonfort, y lenta pero tenazmente, con el respaldo entusiasta de los comerciantes regiomontanos y de las poblaciones fronterizas, fue delineando el sistema arancelario regional que llevaría su nombre y que, en 1858, Tamaulipas inclusive aceptaría oficialmente. ${ }^{9}$

8 Mario Cerutti, Economía de guerra. . . op. cit.; del mismo, "Guerras civiles, frontera norte y formación de capitales en México en años de la Reforma", Boletín Americanista, Universidad de Barcelona, núm. 33, 1983; y "Aduanas, poder regional y Estado nacional en México a mediados del siglo xix". Trienio. Ilustración y liberalismo, núm. 4, Madrid, noviembre, 1984.

9 Mario Cerutti, Aduanas, poder regional. ., op. cit. 
En un contexto de esa naturaleza, condicionado por las urgencias locales y por la guerra, un aluvión de mercancías entró por esta franja territorial adherida a Texas. Si el espacio habitual sobre el que actuaban los comerciantes de Monterrey comprendía el noreste y los estados cercanos del norte oriental (Chihuahua, Zacatecas, Durango, San Luis), con las rebajas verticales que se les concedían, en materia arancelaria prolongaban sus contactos hacia el sur: la ciudad de México, Guanajuato, partes de Jalisco y hasta Colima, sobre el Pacifico, recibían sus introducciones ante el disgusto de los competidores de Veracruz y de la capital.

Aduanas y aranceles, claros instrumentos de un gobierno central cuando logra imponer su soberanía política y administrativa sobre el Estado-nación, permanecían así bajo el dominio de un poder capaz de organizar la actividad militar, política, social y económica en un espacio de dimensiones regionales.

Es pertinente destacar - ya que contribuirá a la argumentación que se desarrollará luego- que la readecuación exigida por la nueva frontera brindó las bases, simultáneamente, para que prominentes comerciantes de Monterrey aprovecharan jugosamente la coyuntura de la guerra de secesión norteamericana (1861-65).

Esta conflagración bélica externa acrecentó drásticamente la circulación mercantil e incentivó la producción agropecuaria en el noreste fronterizo. El algodón fue la clave de este movimiento, pero se agregaron el tráfico de armas, vestimenta, mulas, caballos, cereales, harina y cueros, entre otros artículos consumidos en cantidades considerables por los sitiados ejércitos confederados (con cuyos jefes Vidaurri mantuvo excelentes relaciones).

$\mathrm{Al}$ iniciar los 60, el vidaurrismo se hallaba en su apogeo. Su ordenamiento regional anticipaba en cierta forma lo que Porfirio Díaz plasmaría a escala nacional décadas después. $Y$ el gobernador supo usufructuar la coyuntura, junto con sus comerciantes aliados y amigos. La aduana de Piedras Negras, en Coahuila, que era la que más firmemente controlaba, resultó un punto seguro para la circulación desde y hacia Texas. Evaristo Madero (abuelo del jefe revolucionario) ofrece en su correspondencia particular una rica imagen sobre estos contactos y transacciones con el extremo meridional de Estados Unidos. Madero y comerciantes como Patricio Milmo- un irlandés que era yerno de Vidaurri- se contarían entre los principales beneficiarios del tráfico. ${ }^{10}$

\section{III}

Si los tiempos y actividades del núcleo liberal comandado por Santiago Vidaurri pueden ser útiles para mostrar las características de un sistema de poder político-militar con cierta coherencia, el proceso de formación de capitales protagonizado en Monterrey -y su posterior y llamativo ciclo de crecimiento fabril - servirá para ofrecernos un ejemplo con matices diferentes.

Al convertir en objeto de estudio el surgimiento y desarrollo de la burguesía regiomontana - y ya no el funcionamiento de un sistema

10 Mario Cerutti, Economia de guerra. .., op. cit.; del mismo autor, Burguesía y capitalismo en Monterrey (1850-1910), Claves Latinoamericanas, México, 2a. parte, 1983. 
de poder en momentos de crisis aguda-, al procurar indagar los mecanismos de concentración de bienes y recursos que organizaron esos agentes sociales, el espacio exigió ser redefinido. Pero no dejó, por ello, de ser regional, en tanto supuso una dimensión que rebasaba lo local pero que, a la vez, se contraponía a "lo nacional". Y como en el caso anterior, la dimensión espacial nada tenía que ver con la de un estado-provincia, y escasamente dependía del tamaño de las regiones geográficas.

El estudio fue obligado a seguir, en cambio, el itinerario burgués, los instrumentos que usó este naciente sector dominante para plasmar la tarea que lo perfilaba y definía en términos de la estructura social; es decir, de aquellas herramientas que le facilitaban — según la lógica interna del capital - un empleo eficaz de los caudales, bienes y recursos que centralizaba, y que coadyuvaban a la reproducción ampliada de sus capitales.

La investigación, pues, caminó tras los mercados a los que tenía acceso este segmento social y debió detectar su manejo especulativo del dinero, su vinculación $-\mathrm{o}$ no- con la propiedad de medios eventualmente orientables a la producción. Fue la propia actividad burguesa -cuyo tronco más fértil era entre 1850 y 1890 lo mercantil- la que decidió el tamaño del espacio a auscultar. De nuevo, lo regional estuvo fuertemente sugerido por el objeto de estudio.

¿Cuál fue, entonces, el ámbito sobre el que habrian operado sistemáticamente los comerciantes de Monterrey entre 1850 y 1890 ? Es factible resumir lo siguiente:

1) Las facilidades y oportunidades que Vidaurri brindó al tráfico de intermediación que maniobraba desde Monterrey permitieron que las mercancías cubrieran con cierta regularidad -en los términos de la época- un área que desbordaba los estados del noreste. Desde el punto de vista de la circulación mercantil, el escenario del poder político-militar (Nuevo León/Coahuila/Tamaulipas) fue desbordado hacia los estados vecinos y cercanos. El accionar de esta burguesía involucró focos destacables de Chihuahua, San Luis Potosí, Zacatecas y Durango. Los años 70 y 80 vieron acentuarse estas conexiones mercantiles, tendençia que implicó la instalación de sucursales o casas asociadas en comarcas como la lagunera o en puntos diversos de la frontera del Bravo. ${ }^{11}$

Las nítidas funciones de intermediación que Monterrey ejercía prepararon asimismo las condiciones para que - desde los 90- este mismo espacio fuese un mercado natural para su industria ligera.

2) El préstamo resultó siempre un instrumento paralelo al movimiento comercial. Durante los años de Vidaurri, la economía de

11 Según los libros de notarios del Archivo General del Estado de Nuevo León (AGENL), los comerciantes de Monterrey mantuvieron contactos entre 1850 y 1885 con los siguientes estados y poblaciones: Coahuila, Saltillo, Parras, Zaragoza, Morelos, Gigedo, Río Grande, San Buenaventura, Piedras Negras, San Pedro y toda la zona lagunera, Progreso, Múzquiz, Garza Galán, Villa de Juárez, Rosales; Chihuahua, Chihliahua, Santa Rosalía, Presidio del Norte, Parral, Paso del Norte, Rosales; San Luis Potosí, San Luis, Matehuala, Catorce y diversas comarcas mineras; Tamaulipas, Ciudad Victoria, Matamoros, Villa de Hidalgo, Tampico, Nuevo Laredo, Ciudad Guerrero, Reynosa, Camargo, Mier, Villa de Padilla, Chamal, Jiménez; Zacatecas, Zacatecas, Mazapil, Fresnillo y otras áreas mineras; Durango, Durango, Mapimí, Nazas, San Juan de Guadalupe, Villa de Lerdo, Gómez Palacio, San Fernando. Otras fuentes ratifican y amplían esta geografía de la circulación mercantil en el norte oriental mexicano. 
guerra instaurada había demandado y se había alimentado casi constantemente del crédito de los comerciantes, quienes de esa forma usufructuaban más eficientemente las necesidades imperiosas del poder regional.

Al alterarse tras la reforma las condiciones sociopolíticas globales, y ya en el transcurso de los años 70 , estas actividades funcionaron de manera distinta. Se proyectaron hacia otras parcelas de la actividad económica. Los grandes comerciantes de Monterrey fueron un ejemplo del papel estratégico que asumió el crédito ligado a la vida mercantil en momentos en que no se había plasmado un sistema bancario, una vez suprimida la iglesia como prestamista.

Un caso que hemos analizado en detalle fue el de la Laguna, ${ }^{12}$ comarca que comenzó a producir algodón para abastecer el mercado interior. Las transformaciones que se fueron concretando en la Laguna - particularmente en lo que atañía a la subdivisión, mercantilización e irrigación de la tierra - requirieron un apoyo financiero que en esos años sólo podían ofrecer los comerciantes de envergadura. La documentación revisada certifica el impacto que los capitales regiomontanos - a la par de otros provenientes de la ciudad de México y, en menor escala, de Saltillo- tuvieron en ese impulso productivo. Las "habilitaciones" o refacciones se practicaban en efectivo o en efectos, y la devolución de los préstamos se aseguraba con las cosechas de algodón, que quedaban en prenda (junto, con suma frecuencia, a otros bienes de los agricultores).

3) El movimiento mercantil y el ușo del dinero como mecanismo crediticio motivaron a estos comerciantes a explorar en los 70 y 80 otra vertiente: la apropiación de tierras en vasta escala, ejercicio que en ciertos casos - como los de Evaristo Madero, los Zambrano, los González Treviño o Patricio Milmo- estuvo ligado parcialmente a actividades productivas. Es menester insistir que en estas décadas algunos de los traficantes de Monterrey no perdieron la ocasión de convertirse en destacados terratenientes. Fue un escalón que acompañó la expulsión y exterminio definitivo de los indios seminómadas, la aplicación de las leyes de Reforma y el experimento crediticio de la Laguna. Y que habría de prolongarse desde mediados de los $\mathbf{8 0}$ con las compañías deslindadoras. ${ }^{13}$

A partir de su conversión en gran terrateniente, el ámbito regional ya no interesó a esta burguesía únicamente como intermediaria (como sucedía en tiempos de Vidaurri). Le preocupó también como propietaria de bienes y de medios de producción. Su acontecer cotidiano, acontecer que era el cemento sobre el que se iba definiendo su pertenencia a una clase social diferenciada, ya no se ligaría exclusivamente a la circulación, que genera lazos menos estrechos con espacios relativamente alejados: ahora emergería la propiedad, a la que inevitablemente seguiría la producción.

12 Mario Cerutti, "El préstamo prebancario en el noreste de México. La actividad de los grandes comerciantes de Monterrey (1855-1890)", en Leonor Ludlow y Carlos Marichal (comps.), Banca y poder en México (1800-1925), Enlace-Grijalbo, México, 1986.

13 Mario Cerutti, "Militares, terratenientes y empresarios en el noreste. Los generales Treviño y Naranjo (1880-1910)", en Mario Cerutti (coord.), Monterrey, Nuevo León, el noreste. Siete estudios históricos, Universidad Autónoma de Nuevo León, Monterrey, 1987. 
De allí que sus expectativas desbordasen cuestiones tales como los derechos de importación, las alcabalas, los impuestos a la circulación de moneda. Lo atinente a un mercado de tierras, al derecho de propiedad en el medio rural, al orden jurídico que debía regir sus relaciones de producción, a la acción y aprovechamiento de las compañías deslindadoras, a la promoción y estímulo de las explotaciones mineras (que brotarían con frecuencia en esas extensiones apropiadas), a la posible industrialización de materias agrícolas, pecuarias o del subsuelo (como sucedió a fines de los 80 con la instalación de la fábrica La Esperanza, elaboradora de jabones y aceites a partir de la semilla de algodón), todo esto comenzaría a interesarle directa y cotidianamente. Y nuevos lazos anudarían a esta burguesía con un espacio que insistía en ser mayor que el provincial o el de la región geográfica que incluía a Nuevo León.

Esta base material acentuaría, enriquecería, una visión regional redimensionada, con otros matices, si se la compara con la de los años de Vidaurri. Las condiciones para la aventura inversionista, para una producción capitalista o bajo el dominio del capital, ramifábrica La Esperanza, elaboradora de jabones y aceites a partir de la semilla de algodón), todo esto comenzaría a interesarle directa y expectativas que llevarían a aceptar de muy buen grado el proyecto de nación que instauraría Porfirio Díaz: el Estado-nación ya no se vería interferido por intentos autárquicos, como los que planteó Vidaurri en estas áreas uel país.

\section{IV}

Cuando llegaron los años 90, ese espacio del gran norte oriental mexicano acentuó sus más estrechos vínculos y sus conexiones con Monterrey gracias al ferrocarril, a ciertas singularidades de la producción fabril de la ciudad y a la alta diversificación que de sus capitales efectuaría la burguesía regiomontana.

La trascendencia del ferrocarril derivó, por un lado, a que las principales redes se tendieron hacia Estados Unidos, y atravesaron con insistencia y de manera diversa este inmenso ámbito que involucraba a Nuevo León, Coahuila, Tamaulipas, San Luis Potosí y porciones considerables de Zacatecas y Durango. ${ }^{14}$ Pero, en segundo lugar, todo este espacio fue abruptamente dinamizado por las demandas del mercado norteamericano, lo que obligó a la instalación de líneas complementarias y ramales que unieron no sólo ciudades, sino, a la vez, comarcas productoras de minerales, de carbón, de algodón, forestales, de trigo e ixtle, las ganaderas y frutícolas.

Otras dos consecuencias fueron la activa integración de este espacio a un mercado que tendía a ser nacional, y la transformación de Monterrey en el punto de mayor concentración de vías del sistema. Estaba vinculado a Estados Unidos - de manera directa- por tres líneas troncales (y por una cuarta, indirectamente, mediante Torreón), y conectado con los otros tres núcleos estratégicos del gran norte volcado hacia el Golfo de México: San Luis Potosí, Torreón y el fundamental puerto de Tampico.

14 Mario Cerutti, "El gran norte oriental y la formación del mercado nacional en México a finales del siglo XIX", Siglo xIX. Revista de Historia, Universidad Autónoma de Nuevo León, núm. 4, julio-diciembre, 1987. 
Los ferrocarriles facilitarían simultáneamente que las grandes plantas de fundición que se fincaron en Monterrey - tres a principir s de los 90 , otra al comenzar el siglo $\mathrm{xx}$ - desataran una gigantesca red de demandas que activaron drásticamente la producción minera.

Las modernas empresas dedicadas a la metalurgia básica -matiz que perfiló a Monterrey con nitidez en la América Latina de comien. zos de siglo- provocaron un movimiento de circulación de mercancías orientadas al consumo productivo que, por sí mismo, justificaría la delimitación particularizada del gran norte oriental como espacio digno de estudio, al menos desde la perspectiva de la historia económica. Los minerales en bruto eran traídos desde Durango, Zacatecas, San Luis, Chihuahua, Coahuila, de zonas mineras de Nuevo León. Su transformación en metales se hacía sobre la base de lo que solicitaba el mercado estadunidense y - si se habla de la siderurgia- el propio mercado interior.

Las antiguas relaciones mercantiles quedarian ahora redefinidas. Además, los más prominentes empresarios de Monterrey supieron convertirse en acuciosos inversionistas en el rubro minero, en la explotación ya no del suelo, sino del subsuelo. Entre 1890 y 1905 , miembros de las familias empresariales que hemos estudiado tenían intereses y acciones en dos centenares y medio de explotaciones mineras distribuidas en un $40 \%$ en Coahuila, un $34 \%$ en Nuevo León, un $12 \%$ en Zacatecas, un $9 \%$ en Chihuahua y un $8 \%$ en Durango. ${ }^{15}$

La diversificación de las inversiones de la burguesía regiomontana regionalizó entre 1890 y 1910 al capital. Propiedad de la tierra, aprovechamiento del subsuelo y comercio fueron complementados además con la fundación de casas bancarias, inversiones en transporte urbano y suburbano e industria fabril. ${ }^{16}$

Para contribuir un poco más a una visión algo provocativa de lo regional quisiéramos practicar una breve mención al estado de Texas.

Texas parece haber alcanzado una enorme significación para el tráfico mercantil que se realizaba hacia y desde Monterrey y otros puntos del norte oriental mexicano. Bueno es recordar que se trataba de un territorio que no sólo cubría en su totalidad el espacio que estudiamos, sino que sostuvo un crecimiento demográfico y económico espectacular en la segunda fracción del xIx. Su población pasó de unos 212000 habitantes en 1850 a más de 800000 en 1870 , y el siglo xx fue iniciado con más de 3000000 .

La guerra de secesión resultó una experiencia formidable para ambos lados del Bravo. ${ }^{17}$ Pero ya antes de 1860 se materializaban numerosos intercambios, tanto legales como ilegales - el contra-

15 Mario Cerutti, Burguesía y capitalismo. . ., op. cit.; del mismo, “División capitalista de la producción, industrias y mercado interior. Un estudio regional; Monterrey (1890-1910)", en Mario Cerutti (coord.), El siglo xIX en México. Cinco procesos regionales, Claves Latinoamericanas, México, 1985.

If Mario Cerutti, "Producción capitalista y articulación del empresariado en Monterrey (1890-1910)", en Julio Labastida (comp.), Grupos económicos y organizaciones empresariales en México, Alianza Editorial/unam, México, 1986; Mario Cerutti y Menno Vellinga, Burguesias e industria. ., op. cit.

17 Un ejemplo del lado texano fue el comerciante José San Román, que operaba simultáneamente en Brownsville y Matamoros. Una abrumadora información al respecto puede encontrarse en la San Roman Collection, Eugene Barker Texas History Center, Universidad de Texas en Austin. 
bando se convirtió en una veta riquísima para acumular fortunascomo lo muestran casos como el de Evaristo Madero. ${ }^{18}$ Para las décadas de los 70 y los 80 , la circulación de ganado - verbigracia- se intensificó claramente. Mientras, desde ambas márgenes del Bravo se consumaba un crucial combate contra apaches y comanches, a los que fue menester eliminar o expulsar hacia occidente para abrir más las puertas al desarrollo de la producción y del capital.

El ferrocarril estrecharía aún más los lazos. El crecimiento industrial de Monterrey se vio estimulado en algunos rubros por demandas texanas, y simultáneamente utilizó a casas comerciales del estado norteamericano para su aprovisionamiento de instrumentos y equipos. ${ }^{19}$

Para quien haya seguido con algún detenimiento el devenir de la actividad mercantil y de los núcleos burgueses que trabajaban en Monterrey, no será extraña o descabellada la propuesta de incorporar a Texas al espacio dentro del cual se desarrollaron esos segmentos sociales. ${ }^{20}$ Esto significa que su ámbito regional cobraría un nuevo matiz, en tanto desbordaba la propia línea fronteriza nacional al atravesar barreras jurisdiccionales internacionales.

Lo hasta ahora comentado puede conducir ya a una primera conclusión. La idea de espacio que poco a poco nos vimos impelidos a instrumentar dependió abiertamente del carácter del proceso investigado. No podía delimitarlo ni una jurisdicción político-administrativa (el perímetro de un estado-provincia, o de un municipio), ni un entramado puramente geográfico. Y quizás tampoco una frontera internacional.

El espacio se delimitaba a símismo. El ámbito regional era determinado por los parámetros del objeto de estudio; así se presentaba dotado de una intensa coherencia intèrna, con un sistema de relaciones reconocible en el espacio analizado.

En este sentido compartimos con Eric van Young ${ }^{21}$ algunas afirmaciones, como aquella de que las regiones podrían ser definidas por "la escala de cierta clase de sistema interno". ¿Qué tipo o tipos de sistemas? Van Young responde que hay varios candidatos: "las pautas de la geografía física, la distribución y el tipo de producción económica, la estructura política, el intercambio, las relaciones de mercado".

En discrepancia con la nomenclatura utilizada por este preocupado analista, a nosotros se nos antoja algo gratuito - sin solución a la vista, estrictamente - tratar de definir el concepto región. Como el mismo Van Young lo indica, y como podrían corroborarlo numero-

Is Mario Cerutti, Burguesía y capitalismo..., $2^{\mathrm{a}}$ parte, op. cit.

19 Mario Cerutti, División capitalista. ., op. cit.

20 De allí la investigación que hemos iniciado en archivos texanos con Miguel $A$. González Quiroga, con el apoyo de la Universidad de Texas en Austin. Apunta a esclarecer las relaciones entre el noreste de México y el mercado texano entre 1850 y 1910, con particular atención en su influencia en la formación de capitales en Monterrey.

21 Eric van Young, "Haciendo historia regional. Consideraciones metodológicas y teóricas", en Anuario, Universidad Nacional del Centro de la Provincia de Buenos Aires, núm. 2, 1987. 
sos trabajos generados por diferentes disciplinas, a este concepto -implícita o abiertamente - se le ha otorgado una abrumadora multiplicidad de posibilidades explicativas: desde aquellas que ponen énfasis en los aspectos geográficos hasta las que reconocen la importancia vital de la historia social humana en la configuración regional.

En la medida en que avanzó nuestra experiencia de investigación, y con la alimentación creciente de frutos gestados por colegas dedicados en México y otros países al estudio del siglo xIX -e insistimos en que lo que mencionamos alude a este periodo histórico- fuimos prefiriendo la denominación ámbito regional.

Se trataría de un espacio territorial que puede desbordar - por momentos con amplitud-- una región determinada y reconocida geográficamente; esta área geográfica se vería obligada a quedar resituada - redefinida - por el sistema más general o particular que se estudie. Si el noreste de México - Nuevo León, Coahuila y Tamaulipas - fuese considerado una región por especiales características o parámetros, el ámbito regional que evaluaríamos como más apropiado para indagar la formación de capitales en Monterrey rodearía, envolvería este noreste tras desbordarlo, lo despojaría de la especificidad que le había sido otorgada por la anterior forma de catalogación.

Nos parece de notoria importancia intentar clarificar este aspecto, porque fue en ámbitos como los que aquí procuramos perfilar que se protagonizaron en el siglo XIX procesos históricos fundamentales: tuvieron que ver con la formación de la sociedad capitalista, la configuración del Estado-nación, la constitución y expansión de un mercado tendencialmente nacional y el nacimiento e inicial desarrollo de clases como la burguesía. Eran espacios que rebasaban sin duda los límites de un estado-provincia o de una región fijada por la geografía, pero nunca globalmente mayores —en países de carácter multirregional como México- de lo que sería finalmente el Estado-nación.

Partiendo de que el siglo xix se nutrió de dinamismos enmarcados regionalmente, al preocuparnos por lo acaecido en este tipo de dimensión espacial atenderíamos inevitablemente datos estructuralmente significativos de la realidad investigada.

Admitido semejante peso en términos estructurales, urgiría asignar entonces a la perspectiva regional el fuerte valor metodológico que supone tal capacidad de abordar procesos vertebrales, de alta densidad histórica. Y ello por una razón sencilla y visible: porque el método tiene que responder con eficacia y elasticidad a la realidad viva y densa que pretende abordar y comprender. Dicha perspectiva regional, por otro lado, no será alterada en su esencia porque reconozca que los espacios a estudiar son factibles de modificación según los procesos indagados.

El seguimiento de un grupo social tan prominente como el burgués no puede dejar de lado que fue en este tipo de ámbitos - y no en una provincia o área geográfica cualquiera - donde los integrantes de ese núcleo traficaban, invertían, se convertían en propietarios, ramificaban influencias e intereses. Para su desenvolvimiento, un límite municipal o estatal, una cadena montañosa o una frontera internacional no significaba obstáculo alguno. Por el contrario -y pensamos en el contrabando- podían resultar fuente de enormes ganancias, pues el espacio puede ser modificable, plástico, como las 
distintas vertientes de la historia humana. Si, en cambio, nos detuviéramos en el análisis del sistema político-militar que encabezó Santiago Vidaurri, las dimensiones se acortarían, se empequeñecerian. Lo que permanecería inmodificable - como una exigencia metodológica - es la capacidad instrumental de la perspectiva regional.

Es evidente que desde esta concepción de lo regional (y de lo decimonónico, troncalmente unidos en nuestra propuesta), sólo en casos muy particulares podrían justificarse estudios que aún conservan, en países como México o Argentina, un peso considerable: la historia por estados o provincias. Es una tradición fuertemente arraigada, y suele saturar no sólo lo que sería su marco natural -la historia institucional con sus vertientes políticas-, sino también la historia social y -lo más grave- la historia económica.

Hay que aceptar empero que el espacio provincial o estatal puede ser pertinente en algunos casos. Si, por ejemplo, se analiza el ámbito de aplicación de cierta legislación. ${ }^{22} \mathrm{O}$ si se sostiene, como lo ha hecho José Carlos Chiaramonte ${ }^{23}$ para la Argentina de la primera mitad del xIX, que determinadas dimensiones de lo político y de la actividad económica permanecían restringidas a lo que este autor llamó la región-provincia.

Lo más probable, sin embargo, es que estos objetos de indagación resulten excepcionales en medio de la enorme gama de alternativas que ofrece la perspectiva regional. Y que podría incluir desde la construcción y andanzas de los ejércitos y la circulación de la fuerza de trabajo, hasta la ya referida formación de capitales y de una burguesía, la constitución de un mercado multirregional/nacional, las luchas campesinas, los cambios en los procesos productivos, el combate contra grupos indígenas seminómadas, los mecanismos del crédito o los procesos sociopolíticos que arrastraron a la edificación del estado y del Estado-nación.

Sin dejar de apreciar los aportes indudables que desde las historias provinciales es factible realizar, ${ }^{24}$ quizás sea ya hora de replantear

${ }^{22}$ Es lo que ha efectuado Javier Rojas Sandoval ["Conflictos obreros y legislación laboral en Nuevo León (1885-1918)", en Siglo xIX. Revista de Historia, Universidad Autónoma de Nuevo León, núm. 6, julio-diciembre 1988] al estudiar las variantes que se fueron registrando en la legislación dedicada a los trabajadores en el estado de Nuevo León, entre 1885 y 1918. Es obvio que en este caso, el ámbito de aplicación de las leyes se definiría por la naturaleza jurisdiccional del estado/provincia. Algo similar nos sucedió cuando analizamos el impacto de las leyes de promoción a la inversión adoptadas por el gobierno porfiriano de Bernardo Reyes, y que resultaron decisivas para el crecimiento fabril de Monterrey a fines del siglo [Mario Cerutti, "Poder estatal, actividad económica y burguesía regional en el noreste de México (1855-1910)" en Revista de Historia. . . op. cit., enero-junio, 1986].

23 José Carlos Chiaramonte, "La cuestión regional en el proceso de gestación del Estado nacional argentino", en Marco Palacios (comp.), La unidad nacional de América Latina. Del regionalismo a la nacionalidad, El Colegio de Méxıco, Méxıco, 1983, p. 56. Para Chiaramonte, la provincia es, en realidad, la más sólida dimensión "de lo que podemos llamar región en la Argentina de la primera mitad del siglo xIX. Provincia-región, sólo en la medida en que consideremos la existencia de un espacio mayor que la engloba, el definido por la débil relación que aún en los momentos de mayor fragilidad de los lazos que las unían, continuaron manteniendo las provincias que integrarian la República [. . . ] Provincia-región, unidad sociopolítica, primer fruto estable del derrumbe del imperio español que representa el grado máximo de cohesión social que ofreció la ex colonia al desaparecer las instituciones anteriores.

24 Véase por ejemplo la excelente labor que desarrolla el Instituto Mora, cuyas publicaciones por estado significan un aporte importante, de gran utilidad al conocimiento histórico. 
en profundidad esta manera de producir conocimiento histórico. ${ }^{25}$ Una buena pregunta, en tal sentido, sería la siguiente: ¿es historia regional la historia por provincias o por estados? Si es así, ¿cuáles criterios de espacio utiliza, y para cuáles momentos históricos?

\section{VI}

Antes de concluir estimamos oportuno resumir y agregar - sin mayores comentarios - algunos ejemplos en torno al tipo de espacios que una parte de la más reciente historiografía sobre el México del $\mathrm{xIx}-\mathrm{y}$ sobre las décadas iniciales del $\mathrm{xx}$ - se ha visto obligada a usar. Su punto común es que descarta, como referencia, la región estrictamente geográfica y las jurisdicciones provinciales.

Un caso llamativo lo configuran las investigaciones de Bernardo García Díaz, ${ }^{26}$ centradas en la formación de la clase obrera textil del valle de Orizaba, en el Veracruz finisecular. Conviene de inmediato reproducir una de sus conclusiones. ${ }^{27}$

La clase obrera textil congregada en el valle de Orizaba durante el porfiriato se creó a través del desplazamiento geográfico de cientos de hombres, provenientes de un vasto espacio territorial. De un área amplia que comprendía tanto los territorios (de los estados de) México, Puebla y Tlaxcala. . . como el suriano estado de Oaxaca, y que abarcaba inclusive a otros estados más distantes de Veracruz, como los del Bajío. Dada la extensión del espacio, se localizaban en su seno variadas y diversas regiones, poseedoras cada una de ellas de específicos y singulares rasgos históricos, sociales y culturales. De ellas salieron las migraciones que confluyen en Orizaba desde los años 80 del siglo XIX.

Es evidente cómo el autor - sin hablar de ámbito regional - no se resigna a quedarse en los límites estatales o en una particular región geográfica o cultural. Su objeto de estudio -el surgimiento de sectores proletarios y las migraciones que proveyeron de mano de obra a las modernas plantas textiles de Orizaba - lo indujo a reestructurar, a redimensionar el espacio observado.

Nuestra revisión scibre el abastecimiento de fuerza de trabajo"a la industria fabril de Monterrey, desde los 90 , brindó resultados análogos. Los asalariados llegaban de casi todo el gran norte oriental - la excepción visible era Chihuahua-, pero también de Guanajuato y, en una proporción menor, de Aguascalientes. San Luis era un notable proveedor de trabajadores. ${ }^{28}$

Juan Felipe Leal y Mario Huacuja Rountree pueden, asimismo, ilustrarnos. Su investigación sobre las haciendas pulqueras del centro de México ${ }^{29}$ muestra cómo las zonas productivas fueron alteradas y expandidas cuando el ferrocarril las unió más firme y eficazmente

${ }^{25}$ Y quizás sea ello más imperioso para momentos más recientes que para el siglo XIX, por la evidente centralización protagonizada en México a partir de los años 30 .

${ }_{26}$ Bernardo García Díaz, Un pueblo fabril del porfiriato: Santa Rosa, Veracruz, SEP/80-Fondo de Cultura Económica, México, 1981.

27 Bernardo García Díaz, "La clase obrera textil del valle de Orizaba. Migraciones y origen", en Siglo XIX. Revista de Historia, Universidad Autónoma de Nuevo León, núm. 6, julio-diciembre, 1988, p. 102.

${ }_{28}$ Mario Cerutti, Burguesía y capitalismo..., $4^{\text {a }}$ parte, op. cit.

29 Juan Felipe Leal y Mario Huacuja Rountree, Economía y sistema de haciendas en México. La hacienda pulquera en el cambio: siglo XVIII, XIX y XX, Era, México, cap. II, 1982. 
con el mercado de la ciudad de México. No sólo se registraron transformaciones significativas desde el punto de vista de la producción, del uso de los recursos disponibles, de las relaciones con la fuerza de trabajo y de la tensión que imponía el capital, sino - y es lo que interesa remarcar - en el propio espacio productivo. Los llanos de Apam, en el estado de Hidalgo, quedaron incorporados al ámbito regional en el que reinaban las metamorfoseadas haciendas pulqueras. La perspectiva de los autores debió tener en cuenta esta redefinición del espacio.

Horacio Crespo, ${ }^{30}$ por su lado, perfila cómo la modernización azucarera en Morelos descrita también, entre otros, por Domenico Sindico, ${ }^{31}$ y el perfeccionamiento de los medios de transporte permitieron, a finales del xix, que se dibujara un sistema de precios con las tendencias propias del régimen capitalista. Este sistema se extendía hasta donde lograba penetrar el azúcar de Morelos, cuya capacidad competitiva había crecido con los cambios tecnológicos del ciclo productivo: abarcaba por ello, además de la ciudad de México - su mercado vertebral - otras zonas del centro del país. Empero, Crespo duda en asegurar que el espacio de esta mercancía- y el predominio de sus precios- ocupara todo México. Su ámbito proseguía moviéndose en lo regional, aunque con dimensiones mucho más generosas que en las décadas preferroviarias. ${ }^{32}$

La necesidad de obviar un marco definido por el estado-provincia e hilvanarlo con porciones de una jurisdicción vecina, a partir de las exigencias del objeto de estudio, quedó también manifestada en las indagaciones de Gladys Lizama, ${ }^{33}$ dirigidas a Zamora y su reciente burguesía de finales del xIx. Los propietarios y comerciantes de esta dinámica villa de Michoacán trabajaban provechosamente con una densa fracción de Jalisco, y mostraban poca conexión con el vasto sur de su propio estado. Lizama debió recurrir a una de las luminosas ideas de Luis González para trabajar eficazmente: "estábamos en Jal-Mich..."

Alejandra García Quintanilla ${ }^{34}$ enriqueció las investigaciones sobre el Yucatán henequenero cuando siguió detalladamente los mecanismos del proceso productivo, especialmente en su fase de mecanización y en las exigencias que arreciaron sobre el ritmo de trabajo en el corte de la hoja. La autora llega a hablar de un espacio -el de las plantaciones - construido por el capital. Se trataba de un marco absolutamente diferente al que en el sur de la península anteponía la guerra de castas. El ámbito regional del capital -vinculado al mercado estadunidense y nutrido de un determinado sistema de dominación- era el del norte yucateco. El ámbito de la cultura maya, que

so Horacio Crespo, "El azúcar en el mercado de la ciudad de México, 1885-1910", en Horacio Crespo (coord.), Morelos. Cinco siglos de historia regional, Centro de Estudios Históricos del Agrarismo/Universidad Autónoma de Morelos, México, 1984.

31 Domenico Sindico, "Azúcar y burguesía. Morelos en el siglo Xix", en Mario Cerutti (coord.), El siglo XIX en México..., op. cit.

32 Crespo, comunicación personal.

"Gladys Lizama, "Los capitales zamoranos a principios de siglo", en VII Encuentro sobre la formación del capitalismo en México. El enfoque regional, Morelia, noviembre, 1988, mimeografiado.

34 Alejandra García Quintanilla, "Producción de henequén, producción de hombres (Yucatán, 1850-1910)", en Mario Cerutti (coord.), El siglo XIX en México, op. cit.; Alejandra García Quintanilla, Los tiempos en Yucatán. Los hombres, las mujeres, la naturaleza (siglo $X I X$ ), Claves Latinoamericanas, Méxiço, la. parte, 1986. 
pugnaba por sobrevivir y se alzaba contra ese sometimiento, estaba en el sur: nada tenian qué ver las delimitaciones geográficas o administrativas.

Gilbert Joseph y Allen Wells, ${ }^{35}$ mientras tanto, alteraron o matizaron esos mismos espacios al hablar del sistema de poder y de la resistencia que los trabajadores henequeneros oponían: en sus estudios detectaron franjas circundantes a la zona del henequén que funcionaban para reforzar el aislamiento y facilitar la coerción sobre los peones.

Una gruesa porción de los estudios que actualmente se realizan en México -y otros que sobre el siglo xix comienzan a generalizarse en diversos países latinoamericanos, ${ }^{36}$ así como los que en los últimos quince años se practicaron en España- mostrarían la eficacia de este enfoque. Nuestros comentarios, en esta sucinta ponencia, pretendieron llamar la atención sobre sus frutos: en alguna medida han logrado plantear una interesante reformulación respecto a cómo enfrentar el estudio de un siglo tan fundamental. $\mathrm{O}$, al menos, de algunos de sus procesos vertebrales: su adecuado conocimiento, por otra parte, quizás resulte útil para el esclarecimiento de fenómenos más contemporáneos.

Si la perspectiva regional se insinúa instrumentable para auscultar lo que sucedió tras la fractura del mundo colonial, tendría que evaluarse cuánta calidad ofrece para el análisis de situaciones presentes. Aunque el México de 1990 parece estar muy lejos de aquel que preocupaba a Benito Juárez y a Santiago Vidaurri, lo regional parece continuar vivo en no escasas problemáticas actuales. De ser esto correcto, la perspectiva apuntada cobraría significación para quienes procuran profundizar en los dilemas del aquí y del ahora mexicanos.

35 Gilbert Joseph y Allen Wells, "Estructuras de dominación y formas de resistencia en las haciendas yucatecas a fines del porfiriato", en Siglo XIX. Revista de Historia, Universidad Autónoma de Nuevo León, núm, 6, julio-diciembre, 1988.

${ }^{36}$ Silvia Palomeque ["Los movimientos de población en Cuenca (siglo XIX)", en Siglo XIX. Revista de Historia, Universidad Autónoma de Nuevo León, núm. 7, enerojunio, 1989], al analizar los movimientos de población en Cuenca, Ecuador, durante el siglo XIX, señala lo siguiente en sus conclusiones: "Del conjunto de elementos estudiados podemos percibir una visión donde la región aparece como el espacio propio de reproducción de varios grupos sociales, donde las dinámicas económicas afectan al conjunto y también donde todos se mueven alrededor del eje principal que es la ciudad de Cuenca. Ella será el último punto donde los migrantes probarán suerte antes de emprender el cambio hacia la costa, o donde permanecerán en calidad de 'vagos y malentretenidos', quizás luego de haber migrado dentro de las parroquias rurales hasta que se vean obligados a migrar." Aunque la autora puntualiza la importancia de las delimitaciones (nudos montañosos, variaciones climáticas) que hacen reconocer el encierro de lo geográfico, menciona que a ese "encierro" hay que sumar una "vivencia cotidiana e histórica [que] se ha convertido en espacio conocido y propio". 